\title{
Mental Health Problems in Children with Prader-Willi Syndrome
}

\author{
Norbert Skokauskas MD, PhD'; Eileen Sweeny MD²; Judith Meehan MD, PhD³; \\ Louise Gallagher MD, PhD ${ }^{1}$
}

\section{Abstract}

Background: Prader-Willi Syndrome (PWS) is a genetically determined neurodevelopmental disorder, which occurs in approximately one in 22000 births. Aims: This study aimed to investigate psychiatric characteristics of children diagnosed with PWS compared with an age-, gender- and IQ-matched control group. The parents of children with PWS were assessed for psychological distress in comparison to the parents of the control group. Methodological limitations identified in previous studies were addressed in the present study. Methods: Psychiatric problems were evaluated in a sample of children with genetically confirmed PWS and an age- and IQ-matched control group using the Child Behaviour Checklist 6-18. Parental psychological distress for both groups was evaluated with the Brief Symptom Inventory. Results: Children with PWS had more severe somatic, social, and thought problems, and were more withdrawn-depressed in comparison to controls. Borderline difficulties were detected for the affective, somatic, and attention deficit-hyperactivity CBCL DSMorientated subscales in the PWS group. Parents of PWS children, in comparison to controls, had more somatization, phobic anxiety, obsessive-compulsive, and anxiety problems. Conclusions: PWS represents a complex psychological disorder with multiple areas of disturbances.

Key words: Prader-Willi Syndrome, comorbidity, depression, anxiety disorders, Attention Deficit/Hyperactivity Disorder

\section{Résumé}

Contexte: Le syndrome Prader-Willi (SPW) et un trouble neurodéveloppemental génétique qui touche environ un enfant sur 22 000. Objectif: Étudier les caractéristiques psychiatriques d'enfants ayant reçu un diagnostic de SPW en les comparant à un groupe témoin d'enfants appariés pour l'âge, le et le QI. La détresse psychologique des parents dont les enfants souffraient du SPW a été comparée à celle des parents des enfants du groupe témoin. L'étude a tenu compte des limites méthodologiques constatées dans les études précédentes. Méthodologie: Les problèmes psychiatriques des enfants des deux groupes ont été analysés au moyen de la Liste de contrôle du comportement de l'enfant âgé de 6 à 18 ans. La détresse psychologique des parents des deux groupes a été évaluée au moyen de l'Inventaire des symptômesversion courte. Résultats: Les enfants qui souffrent du SPW ont de plus grandes difficultés au niveau somatique, social et conceptuel, et sont plus repliés sur eux-mêmes ou déprimés que les enfants du groupe témoin. Les sous-échelles État affectif, Somatisation et Déficit d'attention avec hyperactivité basées sur le DSM ont fait apparaître des difficultés à la limite de la pathologie. Les parents des enfants atteints du SPW avaient plus de symptômes somatiques, d'anxiété phobique, de symptômes obsessionnels-compulsifs et de problèmes anxieux que ceux du groupe témoin. Conclusion: Le SPW est un trouble psychologique complexe qui entraîne des perturbations à divers niveaux.

Mots clés: syndrome Prader-Willi, comorbidité, dépression, troubles anxieux, déficit d'attention avec hyperactivité

${ }^{1}$ Trinity College Dublin, Department of Psychiatry, Dublin, Ireland

${ }^{2}$ St. James's Hospital, Dublin, Department of Child Psychiatry, Dublin, Ireland

${ }^{3}$ Trinity College Dublin, Department of Paediatrics, Dublin, Ireland

Corresponding e-mail: N_Skokauskas@yahoo.com

Submitted: July 18, 2011; Accepted: November 11, 2011 


\section{Introduction}

$\mathrm{P}$ rader-Willi Syndrome (PWS) is a genetically determined neurodevelopmental disorder, which occurs in approximately one in 22000 births (Whittington et al., 2001). The critical region has been identified as 15q11-q13, with the majority of PWS cases (approximately 70\%) resulting from a micro-deletion in the chromosome of paternal origin. One quarter of cases are due to maternal uniparental disomy (mUPD), in which two copies of the maternal chromosome are present, and a few cases $(<5 \%)$ are caused by unbalanced translocations or imprinting centre defect (Bittel \& Butler, 2005). Mild to moderate learning disability is usual, with an average IQ of about 70 (Whittington et al., 2001).

The original phenotypic characteristics described by Prader, Labhart and Willi consisted of obesity, short stature, mental retardation, and small hands and feet (Prader, Labhart \& Willi, 1956). The physical phenotype now also includes a narrow bitemporal diameter, almond-shaped palpebral fissures, and a downturned mouth with thin upper lip, hypopigmentation, strabismus, scoliosis and hypogonadism (Bittel \& Butler, 2005). Behavioral problems are also frequent and usually emerge around four years of age, and the characteristic profile is that of obsession with food, temper tantrums, aggression, stubbornness, skin-picking, and controlling and manipulative behavior (Dykens, Leckman, \& Cassidy, 1996; Clarke et al., 2002). Compulsions are similar to the benign and transient rituals observed in normative child development (Feurer et al., 1998; Dykens, 2004). Skin picking has an early onset and shows stability over the time, and prevalence rates range from $65 \%$ to $95 \%$ (Feurer et al., 1998; Dykens, 2004). Variations in phenotype have been noted in relation to the underlying genetic anomaly: paternal deletions are associated with more severe maladaptive behaviours than mUPD mutations, even when IQ is taken into account (Dykens, Cassidy, \& King, 1999). Patients with mUPD have also been shown to be less likely to display skin-picking and high pain-tolerance (Cassidy et al., 1997).

Anecdotally, children with PWS also exhibit other psychological difficulties outside of the described behavioural phenotype. In the past, several studies investigated a broader psychopathological phenotype for PWS. Previous studies did not, however, investigate comorbidity as a primary question, and consequently the potential for sources of artefact, previously described in the literature (Caron \& Rutter, 1991; Wittchen, 1996) in detection of co-morbidity, may not have been considered. Some of the previous studies were purely descriptive in nature, with little or no use of standardized methods for assessing psychiatric problems, or using methods not standardized for subjects with learning difficulties. Other studies employed very small clinical samples (or just case series reports). An absence of control group or the use of control group not matched for age or level of disability is also a common weakness in PWS research (Table 1).
Investigation into parental psychopathology in PWS research in rare. Szatmari et al. investigated parental psychopathology and familial comorbidity in ASD parents, and in this case a PWS sample was used as a control group; other psychological difficulties in PWS parents were not addressed (Szatmari et al., 2008). Thus, there is a relative dearth of literature specifically focused on the mental health of parents with children with PWS.

\section{Aims}

Based on the existent literature, we hypothesised that children with PWS would have a greater degree of psychopathology compared with an age and IQ matched control group. We further hypothesised that parents of children with PWS would have a greater degree of psychological distress compared with children of an age and IQ matched control group. We were interested in exploring the type of psychopathology present in both groups. The present study attempted to address some of the identified methodological limitations in previous investigations.

\section{Methods}

\section{Subjects}

Children with PWS (57) and their parents participating in the First National Irish PWS study were invited to participate. Children only with confirmed PWS based on FISH (fluorescence in situ hybridization) karyotyping were included. Parents were asked to fill in a demographic questionnaire, The Child Behaviour Checklist 6-18, Brief Symptom Inventory. IQ was assessed using Leiter International Performance Scale-Revised. The age, gender and IQ matched control group was collected through Special Schools. Exclusion criteria for this group included children or adolescents with a known clinical diagnosis of PWS, autistic spectrum disorder or any other confirmed genetic syndrome.

\section{Assessment Instruments}

The Child Behaviour Checklist 6-18 (CBCL/6-18) has 118 items which are grouped into Internalising, Externalising and Total scales. The CBCL/6-18 also provides six DSM orientated scales. The CBCL/6-18 has been shown to have good satisfactory reliability and validity in general, clinical, and intellectual disability populations (Borthwick-Duffy, Lane, \& Widaman, 1997; Achenbach \& Rescoria, 2001; Dekker, Koot, van der Ende, \& Verhulst, 2002; Koskentausta, Iivanainen, \& Almqvist, 2004; de Ruiter, Dekker, Verhulst, \& Koot, 2007). Parents reported their own psychological distress using the Brief Symptom Inventory (BSI). The BSI consists of 53 items covering nine symptom dimensions: Somatization, Obsession-Compulsion, Interpersonal Sensitivity, Depression, Anxiety, Hostility, Phobic anxiety, Paranoid ideation and Psychoticism; and three global indices of distress: Global Severity Index (GSI), Positive 
Table 1. Psychiatric Problems in PWS: Literature Review

\begin{tabular}{|c|c|c|c|}
\hline Authors & $\begin{array}{l}\text { Sample size; } \\
\text { instruments employed }\end{array}$ & Main findings & Limitations \\
\hline $\begin{array}{l}\text { (Whitman \& Accardo, } \\
\text { 1987) }\end{array}$ & $\begin{array}{l}35 \text { adolescents with PWS; } \\
\text { Survey Diagnostic Instrument } \\
\text { (SDI) which screens for } \\
\text { the DSM-III criterion-based } \\
\text { diagnostic categories of } \\
\text { neurosis, and hyperactivity }\end{array}$ & $\begin{array}{l}\text { The following diagnostic pattern was } \\
\text { reported: neurosis, dysphoric, ( } 1 \text { probable); } \\
\text { neurosis, compulsive, } 3 \text { ( } 6 \text { probable); } \\
\text { neurosis, anxious, } 4 \text { (and } 10 \text { probable); } \\
\text { somatization, } 0 ; \text { conduct disorder, violent } 0 ; \\
\text { conduct disorder, antisocial, } 0 ; \text { hyperactivity, } \\
1 \text { (and } 1 \text { probable) }\end{array}$ & $\begin{array}{l}\text { DSM-III criterion-based } \\
\text { diagnostic categories were } \\
\text { employed, SDI has no single } \\
\text { standardized quantitative } \\
\text { scoring system, no control } \\
\text { group }\end{array}$ \\
\hline
\end{tabular}

(Curfs, Verhulst, \& 27 individuals with PWS, Fryns, 1991) CBCL

(Dykens, Hodapp, Walsh, \& Nash, 1992)

23 adults and adolescents with PWS, CBCL, Vineland Adaptive Behavior Scale

(Dykens \& Cassidy, 1995)

(Dykens \& Kasari, 1997)

(Beardsmore, Dorman, 25 adults with PWS;

Cooper, \& Webb, 1998) Psychiatric Present StateLearning Disabilities, Adaptive Behaviour Scales

(Clarke, 1998)

(Dykens et al., 1999)

23 individuals with PWS due

(State, Dykens, Rosner, 8 individuals with PWS, Martin, \& King, 1999) Obsessive Compulsive Scale

(Akefeldt \& Gillberg, 1999) age 0.8 to 36.3 ; Modified to paternal deletion and 23 age- and gender-matched subjects with maternal uniparental disomy: $\mathrm{CBCL}$ aged 4 to 20; Yale-Brown

95 adults with PWS; Schedule for Adults with Developmental Disability (PAS-ADD) checklist

44 individuals with PWS, Greenswag Interview of parents with SSBP-PQ, Rutter parent questionnaire and ASSQ. Older Subjects completed the Birleson Depression Inventory and Eating Attitudes Test
$87 \%$ had Total problem scores in the clinical range. No significant difference was found in the proportion of PWS patients scored in the clinical range on the Internalizing over the Externalizing syndrome

Externalising behaviours were significantly higher than internalising across all age groups and adolescent group had the highest externalising domain score

$56 \%$ of children were distracted and irritable, 52 had communication problems; 56 adults/ adolescents were socially inadequate, $74 \%$ impulsive

$72 \%$ obtained clinically elevated Total Scale score in contrast to $23 \%$ and $39 \%$ of the Down Syndrome and mentally retarded samples. PWS scored significantly higher on externalizing behaviour problems than the Down Syndrome sample

The PWS group was found to have higher rates of affective disorders $(17.4 \%)$, in which psychotic symptoms were common, but similar rates of schizophrenia/delusional disorders $(4.3 \%)$ compared with the control group. None was found to have generalized anxiety or phobic disorders

$6.3 \%$ had a possible psychotic disorder in the month before the assessment was made

"deletion" group had significantly higher Internalizing, Externalizing, and Total Child Behaviour Checklist mean raw scores, than did the uniparental disomy group

PWS subjects had greater numbers of obsessive compulsive symptoms resulting in significant impairment

Individuals with PWS had more behavior problems than those in the comparison group. Younger PWS cases had fewer behavior problems than older PWS cases. One woman with PWS developed psychotic symptoms, including agitation, abnormal beliefs and violent aggression problems
Small clinical sample, control group was not match for IQ

Small clinical sample recruited from a private service, no control group

Sample recruited from one PWS Association meeting, no control group

Parents were notified of the study through syndromespecific parent organizations, groups were not matched on weight, and IQ

Small sample, control group not matched for age, IQ

Some reported psychotic symptoms may not be truly indicative of psychotic disorder as a checklist and not a diagnostic tool was employed

Small clinical sample, in some cases old IQ test results used

Very small clinical sample recruited from a tertiary centre

A large proportion of the parents in the non-PWS group also had ID, possibly influencing reporting of behaviours 
Table 1. Psychiatric Problems in PWS: Literature Review (continued)

\begin{tabular}{|llll}
\hline Authors & $\begin{array}{l}\text { Sample size; } \\
\text { instruments employed }\end{array}$ & Main findings & Limitations \\
\hline $\begin{array}{lll}\text { (Einfeld, Smith, } \\
\text { Durvasula, Florio, \& }\end{array}$ & $\begin{array}{l}\text { 46 individuals with PWS; } \\
\text { Developmental Behaviour }\end{array}$ & $\begin{array}{l}63 \% \text { had mood swings without a } \\
\text { reason, 43\% were anxious }\end{array}$ & $\begin{array}{l}30 \% \text { of the controls were in the } \\
\text { mild learning disability range and } \\
\text { Tonge, 1999) }\end{array}$ \\
Checklist (DBC) & & $\begin{array}{l}\text { ascertainment of this group may } \\
\text { well be biased towards those with } \\
\text { greater behaviour disturbance }\end{array}$
\end{tabular}

(Boer et al., 2002) 25 individuals with PWS; clinical assessment

(Verhoeven, Tuinier, \& Curfs, 2003)

(Vogels, Matthijs, Legius, Devriendt, \& Fryns, 2003)

(Steinhausen, Eiholzer, 58 individuals with PWS, aged Hauffa, \& Malin, 2004) 3 to 29; DBC

(Wigren \& Hansen, 2005)

(Kim, Yoo, Cho, Hong, \& Kim, 2005)

(Descheemaeker, Govers, Vermeulen, \& Fryns, 2006)

(Hiraiwa, Maegaki, Okaa, \& Ohnoa, 2007)

(Soni et al., 2007)

(Reddy \& Pfeiffer, 2007)
23 adults with PWS referred for neuropsychiatric assessment; diagnosed according to ICD-10

59 adults with the PWS; clinical assessment

58 children with PWS; Childhood Routines Inventory and Conner's Parent Rating Scale

14 individuals with PraderWilli syndrome, CBCL

59 adults with PWS,

Pervasive Developmental Disorder Mentally Retardation Scale

165 individuals with PWS in Japan assessed by postal questionnaire to parents

46 individuals with PWS, Psychiatric Assessment Schedule for Adults with Developmental Disability, Operational Criteria Checklist for psychotic and Affective illness

73 children and adolescents with PWS; Devereux Scales of Mental Disorders
$28 \%$ had severe affective disorder with psychotic features, with a mean age of onset of 26

18 diagnosed as cycloid psychosis, 5 with bipolar affective disorder

$15.7 \%$ had experienced a psychotic episode with an age of onset varying from 13 to 19 yrs

Behavioural disturbances and psychiatric symptoms increase with increasing age (apart from foodrelated behaviours)

One-fourth showed clinical indices of ADHD, $3.4 \%$ - of anxiety

$71.4 \%$ had social problems, $35 \%$ had attention problems

$19 \%$ met the full diagnostic DSM-III-R criteria for PDD

Young adults with PWS had significantly more behavioural and psychiatric symptoms than those with non-PWS ID with psychotic symptoms in up to $27.6 \%$ over the previous five years

In deletion group ( $\mathrm{N}=24): 41.7 \%$ Non-psychotic depressive illness, 37.5\% Depressive psychosis, $20.8 \%$ Psychotic illness, in mUPD $(n=22)$

$4.5 \%$ Non-psychotic depressive illness, 27.3\% Depressive psychosis, $50 \%$ bipolar affective disorder, $18.2 \%$ psychotic illness

The PWS sample exhibited significantly more attention and acting out and anxiety problems than their peers with mental retardation-only
No standardised assessment, small clinical, sample no control group

Subjects selected from those referred for specialist assessment, no standard instrument used in diagnosis, no comparison between ratters

No standardised instruments, no control group

Subjects recruited from tertiary care centre/parental support groups, lack of formal IQ and genetic information in a sizeable proportion of the sample

Cross-sectional data were collected using postal questionnaires and parents were informants; instruments not validated for ID population

Small clinical sample, PWS diagnosis was made based on clinical assessment

Findings rely on informant-ratings of a screening questionnaire

Questionnaire was not a standardised, validated instrument, no evidence of explanation to parents of terms such as 'hallucination', 'delusion' etc. Parents asked to comment on the prior five years, recall bias likely

Initial screening was performed with invalidated screening questionnaire

Sample was drawn from residential treatment facilities, only one standardized assessment procedure was employed to measure emotional and behavioural problems 
Table 1. Psychiatric Problems in PWS: Literature Review (continued)

\begin{tabular}{|c|c|c|c|}
\hline Authors & $\begin{array}{l}\text { Sample size; } \\
\text { instruments employed }\end{array}$ & Main findings & Limitations \\
\hline $\begin{array}{l}\text { (Zarcone, Peterson, } \\
\text { Breidbord, Ferraioli, } \\
\text { \& Caruso-Anderson, } \\
\text { 2007) }\end{array}$ & $\begin{array}{l}73 \text { individuals with PWS were } \\
\text { assessed using the Yale- } \\
\text { Brown Obsessive Compulsive } \\
\text { Scale and the Compulsive } \\
\text { Behavior Checklist }\end{array}$ & $\begin{array}{l}\text { Individuals with the TI deletion had } \\
\text { more compulsions regarding personal } \\
\text { cleanliness and their compulsions, } \\
\text { Individuals with the T II deletion were } \\
\text { more likely to have compulsions } \\
\text { related to specific academic areas }\end{array}$ & $\begin{array}{l}\text { Although this study is limited } \\
\text { because of the number of statistical } \\
\text { comparisons and the small sample } \\
\text { of individuals with the TI deletion } \\
(n=14)\end{array}$ \\
\hline (Dykens \& Roof, 2008) & $\begin{array}{l}88 \text { individuals with PWS aged } \\
5 \text { to } 51 ; \mathrm{CBCL}\end{array}$ & $\begin{array}{l}\text { No compelling behavioral differences } \\
\text { across PWS paternal deletion } \\
\text { subtypes were found }\end{array}$ & $\begin{array}{l}\text { Cross sectional nature, } \mathrm{CBCL} \\
\text { was used to assess mental health } \\
\text { problems in adults }\end{array}$ \\
\hline (Soni et al., 2008) & $\begin{array}{l}46 \text { individuals with genetically } \\
\text { confirmed PWS; PAS-ADD, } \\
\text { Family History and Life Events } \\
\text { Questionnaires }\end{array}$ & $\begin{array}{l}\text { The profile of psychiatric illness } \\
\text { resembled an atypical affective } \\
\text { disorder with or without psychotic } \\
\text { symptoms }\end{array}$ & No control group \\
\hline (Sinnema et al., 2011) & $\begin{array}{l}98 \text { adults with PWS; } \\
\text { Developmental Behavior } \\
\text { Checklist for Adults (DBC-A) }\end{array}$ & $\begin{array}{l}\text { DBC-A total scores were higher in } \\
\text { the consecutive age groups, with the } \\
\text { most behavioral problems in the oldest } \\
\text { age groups. Persons with mUPD had } \\
\text { higher total scores on the DBC-A than } \\
\text { persons with a deletion }\end{array}$ & $\begin{array}{l}\text { No IQ measure, the study } \\
\text { population is characterized by a } \\
\text { predominance of older persons with } \\
\text { PWS as the sample was "borrowed" } \\
\text { from the study "Ageing in PWS" }\end{array}$ \\
\hline
\end{tabular}

Symptom Distress Index (PDI), and Positive Symptom Total Index (PSI) (Derogatis, 1993). The presence of T-scores greater than 63 on two or more BSI subscales indicates possible psychopathology. A GSI T-score of 63 or greater also indicates possible psychopathology (Derogatis, 1993).

\section{Ethics}

The Irish Health Service Executive's Ethics Committee approved this study. Parents of the children had all signed informed consent forms prior to participation.

\section{Statistical Analysis}

Descriptive statistics were used to characterize the children's and parents' demographic variables, and to evaluate the results of the BSI and the $\mathrm{CBCL} / 6-18$. Correlation analyses using Pearson's Correlation co-efficient were used to compare the results of CBCL/6-18 and BSI to determine the extent to which parents' distress was associated with the identification of externalizing and internalizing problems in PWS children. Analyses were performed with SPSS version 18.0.2.

\section{Results}

\section{Psychopathology in Children with PWS}

Both groups (PWS and controls) were comprised of 24 children. In both groups there were $11(45 \%)$ girls and 13 (55\%) boys. Mean age for PWS boys was nine years $(\mathrm{SD}=3.1$ years) and for PWS girls 11.03 years $(\mathrm{SD}=3.4)$. In the control group mean age for boys was 12 years $(\mathrm{SD}=2.67$ years) and for girls 12 years $(\mathrm{SD}=2.67$ years).
The two groups did not differ significantly with regards to mean age, mean IQ scores, gender. Parents of PWS children were significantly older in comparison to control's parents (Table 2).

The total $\mathrm{T}$ mean score on the $\mathrm{CBCL} / 6-18$ was elevated within the clinical range in PWS and elevated within the borderline range for the control group. No significant differences were found between the two groups for externalizing behaviour problems. The score for internalizing problems score higher in the PWS than controls (T mean score (62.02 $(\mathrm{SD}=10.17)$ vs. $58.13(\mathrm{SD}=7.53) \mathrm{p}<.05)($ Table 3$))$.

The CBCL/6-18 syndromes profile T-scores were elevated within the clinical range for the PWS group for the majority of syndromes. In the PWS group the thought problems item received the highest score (mean $\mathrm{T}=67.71 \mathrm{SD}=9.71$ ) and reached clinically significant range along with the: Withdrawn-depressed (mean $\mathrm{T}=67.71 \mathrm{SD}=8.01$ ); Somatic complaints (mean $\mathrm{T}=63.50 \mathrm{SD}=8.41$ ); Social problems (mean $\mathrm{T}=64.71 \mathrm{SD}=8.95$ ); and, Attention problems (mean $\mathrm{T}=65.92 \mathrm{SD}=9.82)$ items. In the control group clinically significant ranges were reached in rule-breaking behaviour (mean $\mathrm{T}=63.21 \mathrm{SD}=7.2$ ) and attention problems, with attention problems receiving the highest score (mean $\mathrm{T}=64.83$ $\mathrm{SD}=8.93$ ). Borderline clinical ranges were reached on the aggressive problems item in the control group (mean $\mathrm{T}=$ $61.79 \mathrm{SD}=7.84$ ). In the PWS group the rest of the problems (which did not reached clinical range) were within borderline range (Table 3 ).

The comparison of the PWS group and control group along CBCL/6-18 syndromes profiles indicated that children with 


\begin{tabular}{|lcccc|}
\hline \multicolumn{4}{|c|}{ Table 2. Demographic characteristics of PWS and control samples } \\
\hline & $\begin{array}{c}\text { PWS group (N=24) } \\
\text { Mean (SD) }\end{array}$ & $\begin{array}{c}\text { Control group (N=24) } \\
\text { Mean (SD) }\end{array}$ & Test & $P$ \\
\hline Age, years & $9.92(3.6)$ & $11.75(3)$ & $t$ & $>.05$ \\
Gender, male:female & $13: 11$ & $13: 11$ & $t$ & \\
IQ & $64.03(3.1)$ & $65.85(2.9)$ & & $>.05$ \\
Parents' age, years & $45.5(6.2)$ & $51.0(9)$ & $t$ & $<.05$ \\
\hline
\end{tabular}

\begin{tabular}{|lccccc|}
\hline \multicolumn{2}{|c}{ Table 3. CBCL syndrome profiles in PWS and control groups } \\
\cline { 1 - 3 } CBCL/6-18 syndromes profile & \multicolumn{2}{c}{ PWS group } & & \multicolumn{2}{c|}{ Control group } \\
\cline { 2 - 3 } \cline { 5 - 6 } & Mean T score & SD & & Mean T score & SD \\
\hline Anxious/depressed & 62.79 & 8.01 & & 59.54 & 5.59 \\
Withdrawn/depressed & 64.04 & 9.11 & & $55.46^{*}$ & 6.48 \\
Somatic complaints & 63.50 & 8.41 & & $56.13^{*}$ & 6.31 \\
Social problems & 64.71 & 8.95 & & $58.79^{*}$ & 9.41 \\
Thought problems & 67.71 & 9.71 & & $58.04^{*}$ & 7.17 \\
Attention problems & 65.92 & 9.82 & & 64.83 & 8.93 \\
Rule breaking behaviour & 62.88 & 7.2 & & 63.21 & 7.4 \\
Aggressive behaviour & 62.75 & 11.48 & & 61.79 & 7.84 \\
Internalizing Problems & 62.02 & 10.17 & & $58.13^{*}$ & 7.53 \\
Externalizing problems & 62.25 & 9.66 & & 62.46 & 7.66 \\
Total & 64.00 & 10.10 & & 62.29 & 5.71 \\
\hline${ }^{*} P<0.05$ & & & & \\
\hline
\end{tabular}

PWS had more severe somatic problems (mean T 63.50 $\mathrm{SD}=8.41$ vs. $56.13 \mathrm{SD}=6.31, \mathrm{p}<.05$ ), social problems (mean $\mathrm{T} 64.71 \mathrm{SD}=8.95$ vs. $58.79 \mathrm{SD}=9.41, \mathrm{p}<.05)$, thought problems (mean T $67.71 \mathrm{SD}=9.71$ vs. $58.04 \mathrm{SD}=7.17, \mathrm{p}<.05$ ) and were more withdrawn/depressed (mean $\mathrm{T} 64.04$ $\mathrm{SD}=9.11$ vs. $55.46 \mathrm{SD}=6.48, \mathrm{p}<.05)$.

Several behaviours/CBCL items are commonly observed as part of the PWS phenotype (e.g. 'picks nose skin or other parts of the body', 'under active', 'secretive', 'keeps things to self', 'withdrawn', overeats', 'hoards', 'bites fingernails', 'acts too young for his/her age'). These items were analysed separately across the groups (Table 4).

Clinically significant difficulties were not reached for any of CBCL DSM-orientated subscales in either of the groups. Borderline difficulties were detected for the affective, somatic, and attention deficit-hyperactivity CBCL DSMorientated subscales in the PWS group, with PWS children having significantly more somatic (mean $\mathrm{T} 63.05 \mathrm{SD}=8.33$ vs. $52.00 \mathrm{SD}=6.48, \mathrm{P}<.05$ ) and affective (mean $\mathrm{T} 66.22$ $\mathrm{SD}=8.51$, vs. $60.08 \mathrm{SD}=6.829 \mathrm{P}<.05)$ problems than controls (Table 5).

\section{Parental Psychopathology}

The analysis of BSI scales revealed that parents of PWS children in comparison to controls had more somatization, phobic anxiety, obsessive compulsion, and anxiety

\begin{tabular}{|lcc|}
\hline $\begin{array}{l}\text { Table 4. Individual CBCL domains in PWS and } \\
\text { controls }\end{array}$ & $\begin{array}{c}\text { PWS group } \\
\%(\mathrm{~N})\end{array}$ & $\begin{array}{c}\text { Control group } \\
\%(\mathrm{~N})\end{array}$ \\
\hline Domain & $83(20)$ & $45(11)$ \\
\hline $\begin{array}{l}\text { Underactive } \\
\text { Secretive, keeps things }\end{array}$ & $79(19)$ & $33.3(8)$ \\
to self & $75(18)$ & $33.3(8)$ \\
Withdrawn & $96(23)$ & $8.3(2)$ \\
$\begin{array}{l}\text { Picks nose skin or other } \\
\text { parts of the body }\end{array}$ & $96(23)$ & $33.3(8)$ \\
$\begin{array}{l}\text { Overeats } \\
\text { Hoards }\end{array}$ & $66.6(16)$ & $45.8(11)$ \\
Bites fingernails & $58(14)$ & $50(12)$ \\
$\begin{array}{l}\text { Acts too young for his/ } \\
\text { her age }\end{array}$ & $66.6(16)$ & $62.5(15)$ \\
\hline
\end{tabular}

problems (Table 6). Neither group, however, reached clinically significant levels on the GSI scale.

Correlation analyses were used to determine the extent to which parents' distress was associated with the identification of externalising and internalising problems in children with PDW. Table 7 indicates that scores on the BSI indices significantly correlated with scores on the CBCL/6-18 (Table 7). 


\begin{tabular}{|c|c|c|c|c|}
\hline \multirow[b]{2}{*}{ DSM orientated scales } & \multicolumn{2}{|c|}{ PWS } & \multicolumn{2}{|c|}{ Control group } \\
\hline & Mean T score & SD & Mean T score & SD \\
\hline Affective problems & 66.22 & 8.516 & $60.08^{*}$ & 6.829 \\
\hline Anxiety problems & 60.37 & 6.334 & 60.88 & 8.027 \\
\hline Somatic problems & 63.05 & 8.334 & $52.00^{*}$ & 6.487 \\
\hline $\begin{array}{l}\text { Attention deficit/hyperactivity } \\
\text { problems }\end{array}$ & 63.53 & 7.259 & 63.13 & 8.582 \\
\hline Oppositional defiant problems & 61.58 & 5.846 & 58.58 & 7.625 \\
\hline Conduct problems & 62.50 & 7.372 & 63.17 & 6.829 \\
\hline${ }^{*} P<0.05$ & & & & \\
\hline
\end{tabular}

\begin{tabular}{|c|c|c|c|c|}
\hline & \multicolumn{2}{|c|}{ PWS group } & \multicolumn{2}{|c|}{ Control group } \\
\hline & Mean T score & SD & Mean T score & SD \\
\hline Somatization & 60.15 & 5.66 & $55.81^{*}$ & 6.54 \\
\hline Depression & 57.00 & 6.89 & 57.32 & 5.43 \\
\hline Phobic Anxiety & 63.02 & 4.67 & $55.21^{*}$ & 5.33 \\
\hline Obsessive-Compulsive & 68.96 & 5.66 & $59.96^{*}$ & 6.02 \\
\hline Anxiety & 64.08 & 3.55 . & $54.15^{*}$ & 5.03 \\
\hline Interpersonal Sensitivity & 65.13 & 7.64 & 58.67 & 6.43 \\
\hline Paranoid Ideation & 57.94 & 6.54 & 58.44 & 6.23 \\
\hline Hostility & 59.56 & 6.32 & 58.08 & 4.65 \\
\hline Psychoticism & 54.88 & 6.43 & 58.2 & 3.56 \\
\hline GSI & 62.29 & 5.34 & 58.38 & 5.65 \\
\hline
\end{tabular}

Table 7. Correlations between BSI scores and CBCL/6-18

\begin{tabular}{|c|c|c|}
\hline & \multicolumn{2}{|c|}{ CBCL } \\
\hline & Internalising & Externalizing \\
\hline $\begin{array}{l}\text { BSI GSI Pearson } \\
\text { Correlation Sig. (2-tailed) }\end{array}$ & $.623^{*}$ & $.702^{*}$ \\
\hline $\begin{array}{l}\text { BSI PDI Pearson } \\
\text { Correlation Sig. (2-tailed) }\end{array}$ & $.429^{*}$ & $.412^{*}$ \\
\hline $\begin{array}{l}\text { BSI PSI Pearson } \\
\text { Correlation Sig. (2-tailed) }\end{array}$ & $.611^{*}$ & $.509^{*}$ \\
\hline${ }^{*}$ Correlation is significant at & . & \\
\hline
\end{tabular}

\section{Discussion}

The present study investigated psychiatric problems in children diagnosed with PWS, their parents' psychological problems, and compared them with an age-, gender- and IQ-matched control group and their parents. The main findings from this study can be summarized as follows. The Internalizing problems score was higher in children with PWS than controls. On CBCL/6-18 syndromes profiles the PWS group showed significantly more somatic, social, thought problems and were more withdrawn-depressed and then control group. Borderline difficulties were reached on the affective, somatic and attention deficit/hyperactivity CBCL DSM orientated subscales in the PWS group, with PWS children having significantly more somatic and affective problems than controls. Parents of PWS children in comparison to controls had more somatization, phobic anxiety, obsessive compulsion, and anxiety problems.

While the internalizing problems score was higher in children with PWS than controls, the internalising problems score was smaller in the PWS subjects compared with externalising problems; this is in keeping with several previous studies (Dykens et al., 1992; Dykens \& Kasari, 1997). One older study however, found no significant difference in the proportion of PWS patients scored in the clinical range on the Internalizing over the Externalizing syndrome (Curfs et al., 1991).

It has been well documented that children with learning difficulties show a greater risk for psychopathology compared to typically developing children and several studies have shown that, within a given mild intellectual disability population, between $24 \%$ and $54 \%$ of subjects present serious emotional, social and behavioural problems (Dekker et al., 2002; Capozzi et al., 2008). In our study, children and adolescents with PWS exhibited more comorbid psychological 
problems than their peers matched for age, IQ, and gender. Indeed, our findings illustrate that children with PWS exhibit psychological difficulties that extend beyond the historical perception that the syndrome is marked only by maladaptive behaviours, obsessive-compulsive traits, and skin picking.

Our study has found that PWS subjects displayed very high levels of thought problems on CBCL/6-18. It has to been explained that CBCL "thought problems" domain includes items such as "seeing things", "hearing voices", "strange ideas". Several previous reports and studies have suggested an association between PWS and psychotic episodes and few studies reported that psychotic symptoms were present in almost a half of the sample (see Table 1). However in the present study (and in other studies which employed CBCL/6-18), high levels of "thought problems" on CBCL/6-18 reflect not only a potential link between psychotic problems and PWS, but also a very clear link between skin picking and PWS because the "thought problems" item also includes a question about skin picking (Table 3).

In the present study we reported high scores on the CBCL Withdrawn-depressed item in children with PWS. Kim et al. reported much lower scores on the withdrawn-depressed item (mean T-score 52.21 SD=10.28 vs. mean T-score 64.04 $\mathrm{SD}=9.11$ ), yet these authors acknowledged a possibility that their results might have been influenced by factors associated with sociocultural characteristics i.e. Korean parents being less sensitive to their children's emotional states, such as depression, and the greater weight they give to externalizing problems (Kim et al., 2005). Studies carried out in Western Europe and North America have produced similar rates of affective problems in children with PWS to this study (Boer et al., 2002).

In the past, very little attention was paid to ADHD-type difficulties in children with PWS. A prior study investigating ADHD in PWS, found that a quarter showed clinical indices of ADHD (Wigren \& Hansen, 2005). In our study attention deficit-hyperactivity CBCL DSM orientated subscale has reached borderlines scores in $21 \%$ of the children with PWS. Previously it has been reported that autism spectrum disorders (ASD) could be linked with maternally-derived duplications or triplications of chromosome 15q11-13, and therefore might occur more frequently in people with PWS due to uniparental disomy (UPD), than in other forms of chromosomal abnormality involving this region (Veltman et al., 2004). Our study did not employ ASD diagnostic instruments yet children with PWS exhibited more severe social problems in comparison with controls.

Distress and psychiatric problems in parents of children with PWS have received surprisingly very little attention in previous research. Few previous studies have investigated stress levels and profiles in parents of children with PWS, and none looked at their psychiatric difficulties. Hodapp reported that parents of children with PWS showed higher levels of parent and family problems, and comparable levels of pessimism to parents of children with mixed aetiologies of retardation (Hodapp, Dykens, \& Masino, 1997). This study, however, did not have clear inclusion criteria, and the control sampled was "borrowed" from other studies. Wulffaert et al. reported that parenting stress was high for $26 \%$ of PWS cases when measured with the Nijmegen Parenting Stress Index-Short (Wulffaert, Scholte, \& Van Berckelaer-Onnes, 2010).

To our knowledge our study is the first study to investgate psychological difficulties in parents of PWS children. The present study found that parents of PWS children in comparison to controls had more somatization, phobic anxiety, obsessive compulsion, and anxiety problems and that these correlate with measures of psychopathology in PWS children.

Our study has several limitations and strengths. Firstly, the PWS sample was not large. Based on an estimated incidence of one in 22000 live births (Whittington et al., 2001), our nationwide sample nonetheless constitutes about $14 \%$ of the total Irish PWS population. Our sample consisted of subjects aged from 6 to 18 , and the representation would be even higher within this age range. Accurate epidemiological data regarding the Irish PWS population within the age range of 6-18 is unfortunately not available at present. Secondly, in our study only one standardized instrument was employed to measure emotional and behavioural problems in children with PWS. A third limitation is that we did not match across the two groups on the degree of obesity.

Despite the limitations described above, this was the first study in Ireland to investigate psychiatric and behavioural characteristics of children with PWS, and our study extends the findings of other studies regarding the presence of specific psychiatric difficulties, which requires psychiatric attention, and in some case psychiatric interventions. Moreover this was the first study, which specifically investigated psychological difficulties in parents of children with PWS and compared them with parents of children with learning disabilities.

\section{Conclusions and Future Directions:}

1. PWS represents a complex psychological disorder with multiple areas of disturbances.

2. Children with PWS had more somatic, social and thought problems, and were more withdrawn-depressed and then were those in the control group.

3. Parents of PWS children in comparison to those of controls had more somatization, phobic anxiety, obsessive compulsion, and anxiety problems.

4. Parents' distress was associated with the severity of psychological problems in children with PWS.

5. Epidemiological samples are required to further explore psychiatric problems in chidren with PWS 
and their parents, and future studies should employ a multimodal assessment approach, which includes multiple measures and multiple informants across settings.

\section{Acknowledgements / Conflicts of Interest}

Authors thank all participants for their willingness to contribute to advance medical science in the field of PWS. The authors have no financial relationships to disclose.

\section{References}

Achenbach, T. M., \& Rescorla, L. A. (2001). Manual for ASEBA School-Age Forms \& Profiles. Burlington, VT: University of Vermont, Research Center for Children, Youth, \& Families.

Akefeldt, A., \& Gillberg, C. (1999). Behavior and personality characteristics of children and young adults with Prader-Willi Syndrome: A controlled study. Journal of the American Academy of Child \& Adolescent Psychiatry, 38(6), 761-769.

Beardsmore, A., Dorman, T., Cooper, S. A., \& Webb, T. (1998). Affective psychosis and Prader-Willi syndrome. Journal of Intellectual Disability Research, 42, 463-471.

Bittel, D. C., \& Butler, M. G. (2005). Prader-Willi syndrome: Clinical genetics, cytogenetics and molecular biology. Expert Reviews in Molecular Medicine, 7(14), 1-20.

Boer, H., Holland, A., Whittington, J., Butler, J., Webb, T., \& Clarke, D. (2002). Psychotic illness in people with Prader Willi syndrome due to chromosome 15 maternal uniparental disomy. Lancet, 359(9301), 135-136.

Borthwick-Duffy, S. A., Lane, K. L., \& Widaman, K. F. (1997). Measuring problem behaviors in children with mental retardation: Dimensions and predictors. Research in Developmental Disabilities, 18(6), 415-433

Capozzi, F., Casini, M. P., Romani, M., De Gennaro, L., Nicolais, G., \& Solano, L. (2008). Psychiatric comorbidity in learning disorder: Analysis of family variables. Child Psychiatry and Human Development, 39(1), 101-110.

Caron, C., \& Rutter, M. (1991). Comorbidity in child psychopathology: Concepts, issues and research strategies. The Journal of Child Psychology and Psychiatry and Allied Disciplines, 32(7), 1063-1080.

Cassidy, S. B., Forsythe, M., Heeger, S., Nicholls, R. D., Schork, N., Benn, P., \& Schwartz, S. (1997). Comparison of phenotype between patients with Prader-Willi syndrome due to deletion $15 \mathrm{q}$ and uniparental disomy 15. American Journal of Medical Genetics, 68(4), 433-440.

Clarke, D. (1998). Prader-Willi syndrome and psychotic symptoms: 2. A preliminary study of prevalence using the Psychopathology Assessment Schedule for Adults with Developmental Disability checklist. Journal of Intellectual Disability Research, 42(6), 451-454.

Clarke, D. J., Boer, H., Whittington, J., Holland, A., Butler, J., \& Webb, T. (2002). Prader-Willi syndrome, compulsive and ritualistic behaviours: The first population-based survey. British Journal of Psychiatry, 180, 358-362.

Curfs, L. M., Verhulst, F. C., \& Fryns, J. P. (1991). Behavioral and emotional problems in youngsters with Prader-Willi syndrome. Genetic Counseling, 2(1), 33-41.

de Ruiter, K. P., Dekker, M. C., Verhulst, F. C., \& Koot, H. M. (2007). Developmental course of psychopathology in youths with and without intellectual disabilities. The Journal of Child Psychology and Psychiatry and Allied Disciplines, 48(5), 498-507.

Dekker, M. C., Koot, H. M., van der Ende, J., \& Verhulst, F. C. (2002). Emotional and behavioral problems in children and adolescents with and without intellectual disability. The Journal of Child Psychology and Psychiatry and Allied Disciplines, 43(8), 1087-1098.
Derogatis, L. R. (1993). BSI Brief Symptom Inventory Administration. Procedures Manual (4th Ed.). Minneapolis, MN: National Computer Systems.

Descheemaeker, M. J., Govers, V., Vermeulen, P., \& Fryns, J. P. (2006). Pervasive developmental disorders in Prader-Willi syndrome: The Leuven experience in 59 subjects and controls. American Journal of Medical Genetics Part A, 140A, 1136-1142.

Dykens, E. M. (2004). Maladaptive and compulsive behavior in PraderWilli syndrome: New insights from older adults. American Journal on Mental Retardation, 109(2), 1421-53

Dykens, E. M., \& Cassidy, S. B. (1995). Correlates of maladaptive behavior in children and adults with Prader-Willi syndrome. American Journal of Medical Genetics, 60, 546-549.

Dykens, E. M., Cassidy, S. B. \& King, B. H. (1999). Maladaptive behavior differences in Prader-Willi syndrome due to paternal deletion versus maternal uniparental disomy. American Journal on Mental Retardation, 104(1), 67-77.

Dykens, E. M., Hodapp, R. M., Walsh, K., \& Nash, L. J. (1992). Adaptive and maladaptive behavior in Prader-Willi syndrome. Journal of the American Academy of Child \& Adolescent Psychiatry, 31(6), 1131-1136.

Dykens, E. M., \& Kasari, C. (1997). Maladaptive behavior in children with Prader-Willi syndrome, Down syndrome, and nonspecific mental retardation. American Journal on Mental Retardation, 102(3), 228-237.

Dykens, E. M., Leckman, J. F., \& Cassidy, S. B. (1996). Obsessions and compulsions in Prader-Willi syndrome. The Journal of Child Psychology and Psychiatry and Allied Disciplines, 37(8), 995-1002.

Dykens, E. M., \& Roof, E. (2008). Behavior in Prader-Willi syndrome: Relationship to genetic subtypes and age. Journal of Child Psychology and Psychiatry, 49, 1001-1008.

Einfeld, S. L., Smith, A., Durvasula, S., Florio, T., \& Tonge, B. J. (1999). Behavior and emotional disturbance in Prader-Willi syndrome. American Journal of Medical Genetics, 82, 123-127.

Feurer, I. D., Dimitropoulos, A., Stone, W. L, Roof, E., Butler, M. G., \& Thompson, T. (1998). The latent variable structure of the Compulsive Behaviour Checklist in people with Prader-Willi syndrome. Journal of Intellectual Disability Research, 42(6), 472-480.

Hiraiwaa, R., Maegakia, Y., Okaa, A., \& Ohnoa, K. (2007). Behavioral and psychiatric disorders in Prader-Willi syndrome: A population study in Japan. Brain and Development, 29(9), 535-542.

Hodapp, R. M., Dykens, E. M. \& Masino, L. L. (1997). Families of children with Prader-Willi syndrome: Stress-support and relations to child characteristics. Journal of Autism and Developmental Disorders, 27(1), 11-24.

Kim, J. W., Yoo, H. J., Cho, S. C., Hong, K. E., \& Kim, B. N. (2005). Behavioral characteristics of Prader-Willi syndrome in Korea: Comparison with children with mental retardation and normal controls. Journal of Child Neurology, 20(2), 134-138.

Koskentausta, T., Iivanainen, M., \& Almqvist, F. (2004). CBCL in the assessment of psychopathology in Finnish children with intellectual disability. Research in Developmental Disabilities, 25(4), 341-354.

Prader, A., Labhart, A., \& Willi H. (1956). Ein Syndrom von Adipositas, Kleinwuchs, Kryptorchismus und Oligophrenie nach Myatonieartigem Zustand im Neugeborenenalter. Schweizerische medizinische Wochenschrift, 86, 1260-1261.

Reddy, L. A., \& Pfeiffer, S. I. (2007). Behavioral and Emotional Symptoms of Children and Adolescents with Prader-Willi Syndrome. Journal of Autism and Developmental Disorders, 37(5), 830-839.

Sinnema, M., Einfeld, S. L., Schrander-Stumpel, C. T., Maaskant, M. A., Boer, H., \& Curfs, L. M. (2011). Behavioral phenotype in adults with Prader-Willi syndrome. Research in Developmental Disabilities, 32(2), 604-612.

Soni, S., Whittington, J., Holland, A. J., Webb, T., Maina, E. N., Boer, H., $\&$ Clarke, D. (2007). The course and outcome of psychiatric illness in people with Prader-Willi syndrome: implications for management and treatment. Journal of Intellectual Disability Research, 51, 32-42. 
Soni, S., Whittington, J., Holland, A. J., Webb, T., Maina, E. N., Boer, H., \& Clarke, D. (2008). The phenomenology and diagnosis of psychiatric illness in people with Prader-Willi syndrome. Psychological Medicine, 38(10), 1505-1514.

State, M. W., Dykens, E. M., Rosner, B., Martin, A., \& King, B. H. (1999). Obsessive-compulsive symptoms in Prader-Willi and "PraderWilli-Like" patients. Journal of the American Academy of Child \& Adolescent Psychiatry, 38(3), 329-334.

Steinhausen, H. C., Eiholzer, U., Hauffa, B. P., \& Malin, Z. (2004). Behavioural and emotional disturbances in people with Prader-Willi Syndrome. Journal of Intellectual Disability Research, 48(1), 47-52.

Szatmari, P., Georgiades, S., Duku, E., Zwaigenbaum, L., Goldberg, J., $\&$ Bennett, T. (2008). Alexithymia in parents of children with autism spectrum disorder. Journal of Autism and Developmental Disorders, 38(10), 1859-1865.

Veltman, M. W. M., Thompson, R. J., Russell, J., Roberts, S. E., Thomas, N. S., Whittington, J. \& Bolton, P. F. (2004). Prader-Willi syndrome - a study comparing deletion and uniparental disomy cases with reference to autism spectrum disorders. European Child and Adolescent Psychiatry, 13(1), 42-50.

Verhoeven, W. M. A., Tuinier, S., \& Curfs, L. M. G. (2003). PraderWilli syndrome: Cycloid psychosis in a genetic subtype?. Acta Neuropsychiatrica, 15, 32-37.
Vogels, A., Matthijs, G., Legius, E., Devriendt, K., \& Fryns, J. (2003). Chromosome 15 maternal uniparental disomy and psychosis in PraderWilli syndrome. Journal of Medical Genetics, 40(1), 72-73.

Whitman, B. Y., \& Accardo, P. (1987). Emotional symptoms in PraderWilli syndrome adolescents. American Journal of Medical Genetics, 28(4), 897-905.

Whittington, J. E., Holland, A. J., Webb, T., Butler, J., Clarke, D., \& Boer, H. (2001). Population prevalence and estimated birth incidence and mortality rate for people with Prader-Willi syndrome in one UK Health Region. Journal of Medical Genetics, 38(11), 792-798.

Wigren, M., \& Hansen, S. (2005). ADHD symptoms and insistence on sameness in Prader-Willi syndrome. Journal of Intellectual Disability Research, 49(6), 449-456.

Wittchen, H. U. (1996). Critical issues in the evaluation of comorbidity of psychiatric disorders. British Journal of Psychiatry, Suppl(30), 9-16.

Wulffaert, J., Scholte, E. M., \& Van Berckelaer-Onnes, I. A. (2010). Maternal parenting stress in families with a child with Angelman syndrome or Prader-Willi syndrome. Journal of Intellectual Disability Research, 35(3), 165-174.

Zarcone, D. N., Peterson, C., Breidbord, J., Ferraioli, S., \& CarusoAnderson, M. (2007). The relationship between compulsive behaviour and academic achievement across the three genetic subtypes of PraderWilli syndrome. Journal of Intellectual Disability Research, 51(6), 478-487.

\section{Call for Applications for Editor}

of the

\section{Journal of the Canadian Academy of Child and Adolescent Psychiatry}

Published quarterly, the JCACAP (Indigo Journal) is a journal unique among other competing world journals yet maintaining a Canadian perspective and providing an interdisciplinary approach to child mental health. The JCACAP is sited in many databases including PubMed, PsycINFO, CINAHL, Scopus, EMBASE, and Excerpta Medica.

The Editor is supported by two assistant editors as well as subsection editors and a management team consisting of a Manager of Advertising and Production, an Editorial Assistant, and a Graphic Designer. The position is a 3-year term once renewable and begins in June 2012.

Qualities for the position include:

- Significant knowledge and experience regarding publication of scientific articles

- Significant knowledge and experience regarding the peer review process

- Ability to build knowledge translation between research and the clinical practice of child and adolescent psychiatry

- Significant contacts nationally and internationally in academic child and adolescent psychiatry

- Excellent interpersonal, leadership, and organizational skills

If you are an individual with the above qualities and full of energy, creativity and enthusiasm for this position, please send your $\mathrm{CV}$ and letter of interest to the following coordinates:

Elizabeth Waite, Executive Director, CACAP National Office

701 - 141 Laurier Avenue West,

Ottawa, ON K1P 5J3

Fax: 613-234-9857; Tel: 613-288-0408

elizabeth.waite@cacap-acpea.org 